\title{
Pengembangan Pocket Book Mathematic (Pockemath) Berbasis Android Sebagai Media Pembelajaran Siswa
}

\author{
Nurmala R ${ }^{1}$, Aprilia Sri Eka Udiana ${ }^{2}$ \\ Universitas Borneo Tarakan ${ }^{1,2}$ \\ Email: nurmala.r17@gmail.com¹, aprilia.minb@gmail.com²
}

\begin{abstract}
Abstrak. Teknologi merupakan salah satu sarana yang dapat menunjang proses pembelajaran di sekolah. Salah satu bentuk pemanfaatan teknologi dalam pembelajaan adalah penggunaan Pocket Book Mathematic sbagai media pembelajaran dengan menggunakan smartphone.Penelitian ini adalah penelitian pengembangan (Research and Development) yang bertujuan untuk menghasilkan sebuah produk berupa Pocket Book Mathematic (Pockemath) Berbasis Android Sebagai Media Pembelajaran untuk siswa. Pengembangan Pocket Book Mathematic (Pockemath) Berbasis Android ini mengacu pada Model Thiagarajan Four-D yang meliputi 4 tahap: Define, Design, Develope dan Desseminates. Pengumpulan data menggunakan instrumen penelitian yaitu dokumentasi, observasi, lembar penilaian validator, dan angket respon siswa. Analisis data dilakukan dengan Uji layak dan uji kepraktisan produk Pockemath. Hasil penelitian ini adalah produk berupa Pocket Book Mathematic (Pockemath) berbasis android yang layak dan praktis digunakan sebagai media pembelajaran untuk siswa. Hal ini berdasarkan analisis data diperoleh penilaian validator dengan persentase $80,55 \%$ pada kategori sangat layak dan hasil data respon siswa sebesar $91,19 \%$ dengan kategori sangat praktis.
\end{abstract}

\section{Kata Kunci: Pengembangan, Pockemath, Android, Media Pembelajaran}

\begin{abstract}
Technology is one of the means that can support the learning process in schools. One form of using technology in learning is the use of Pocket Book Mathematics as a learning medium by using a smartphone. This research is a research and development (Research and Development) which aims to produce a product in the form of Pocket Book Mathematics (Pockemath) Based on Android as Learning Media for students. The development of Pocket Book Mathematical (Pockemath) based on Android refers to the Thiagarajan Four-D Model which includes 4 stages: Define, Design, Develop and Desseminates. Collecting data using research instruments, namely documentation, observation, validator assessment sheets, and student response questionnaires. Data analysis was carried out with a feasible test and a Pockemath product practicality test. The result of this research is a product in the form of Pocket Book Mathematics (Pockemath) based on android which is feasible and practical to be used as a learning medium for students. This is based on the analysis of the data obtained by the validator's assessment with a percentage of $80.55 \%$ in the very feasible category and the results of student response data of $91.19 \%$ in the very practical category.
\end{abstract}

\section{Keywords: Development, Pocketmath, Android, Learning Media}

\section{A. Pendahuluan}

Perkembangan kemajuan teknologi sangat cepat dan amat pesat dalam kehidupan sekarang ini yang tidak memungkinkan untuk bisa dihindari. Dengan perkembangan teknologi yang demikian dapat dimanfaatkan dalam pendidikan khususnya dalam pembelajaran, misalnya memanfaatkan teknologi sebagai media dalam pembelajaran untuk menyampaikan materi pembelajaran di dalam kelas. Hal ini sejalan dengan pendapat Akhmadan (Masykur, 2017: 178) bahwa salah satu cara penggunaan teknologi dalam pembelajaran yaitu memanfaatkan sumber daya teknologi sebagai media dalam proses pembelajaran. Sehingga diperlukan sebuah media pembelajaran berbasis teknologi yang dapat memudahkan siswa dalam proses pembelajaran baik di dalam maupun di luar kelas. Media pembelajaran berbasis teknologi yang dapat dimanfaatkan salah satunya adalah smartphone android. 
Berdasarkan hasil wawancara yang dilakukan oleh peneliti pada guru matematika dan peserta didik di salah satu Sekolah Menengah di Kota Tarakan, ditemukan bahwa kurangnya minat belajar peserta didik ketika menerima pelajaran. Siswa cepat merasa bosan dalam pembelajaran matematika, buku paket yang tebal membuat siswa kurang tertarik belajar, media yang disajikan dalam pembelajaran daring berupa Power point yang sering digunakan terkesan kurang menarik bagi siswa dan kurang efektif dalam implementasinya sehingga semangat belajar peserta didik mengalami penurunan. Kurangnya buku pendukung lainnya yang dapat digunakan dan memudahkan peserta didik dalam belajar matematika, juga menjadi permasalahan dalam proses pembelajaran misalnya buku saku. Sehingga perlu adanya suatu hal yang baru bagi siswa yaitu dengan pengembangan media pembelajaran yang layak dan praktis dalam mengatasi permasalah-permasalahan diatas.

Peserta didik menginginkan buku yang praktis agar mudah digunakan saat ingin belajar dimanapun dan kapanpun yang lebih menarik dengan materi yang lengkap dengan gambar yang berwarna. Kondisi di atas memerlukan solusi untuk memotivasi peserta didik dalam meningkatkan minat dan kemandirian belajar dalam membaca buku pelajaran matematika, sehingga diperlukan buku suplemen tambahan untuk memudahkan peserta didik belajar. Peneliti merasa penting untuk mengembangkan sebuah bahan ajar berupa media pembelajaran untuk mata pelajaran matematika yang didesain secara menarik dan praktis sebagai bahan ajar tambahan bagi peserta didik selain buku paket dan powerpoint yang disajikan dalam bentuk pocket book mathematic dengan pokok bahasan bangun ruang.

Sehingga salah satu solusinya adalah dengan media pembelajaran yang berbasis teknologi agar tampilan dan gaya belajar lebih menarik serta membuat siswa terhindar dari rasa jenuh dan bosan saat mengikuti pembelajaran. Media pembelajaran yang memanfaatkan teknologi mobile learning merupakan salah satu alternatif pengembangan media pembelajaran yang inovatif (Negara, 2019: 42).

National Education Association (NEA) mendefinisikan media sebagai segala benda yang dapat dimanipulasikan, dilihat, didengar, dibaca atau dibicarakan beserta instrumen yang dipergunakan untuk kegiatan tersebut (Muhson, 2010: 2). Briggs (Sadiman, 2014: 6) berpendapat bahwa "Media adalah segala alat fisik yang dapat menyajikan pesan serta merangsang siswa untuk belajar". Sedangkan Hamalik mendefinisikan: "Media sebagai teknis yang digunakan dalam rangka lebih mengefektifkan komunikasi antara guru dan murid dalam pembelajaran".

Media pembelajaran tersebut dikemas dalam bentuk aplikasi berbasis Android yang tidak hanya menampilkan unsur menarik tetapi juga unsur pembelajaran matematika untuk siswa. Media edukasi ini diharapkan mampu meningkatkan daya tarik siswa dalam mengikuti pelajaran Matematika. Oleh karena itu, peneliti membuat pengembangan media berbasis android, dimana media tersebut menggunakan Construct 2. Construct 2 dirancang untuk pemula (non programmers) yang ingin menciptakan media pembelajaran tanpa menggunakan bahasa pemrograman yang rumit seperti software lainnya. Menurut Gullen (Apriyanto, 2016: 67) "Construct 2 adalah sebuah tool berbasis Hyper Text Markup Language (HTML) 5 untuk menciptakan sebuah game. HTML 5 merupakan bahasa markup untuk penataan dan penyajian konten untuk World Wide Web dan merupakan teknologi inti dari jaringan internet yang pada awalnya diusulkan oleh Opera Software. Construct 2 berbeda dengan tools lain yang mengharuskan pemrogram menuliskan baris demi baris agar tercipta sebuah objek. Hal ini karena Construct 2 sudah berbasis objek sehingga sangat mudah dalam membuat objek-objek dan mengatur atribut-atribut dari objek tersebut. Construct 2 juga memiliki fitur-fitur yang mudah digunakan dan dimengerti oleh pemrogram pemula.

Construct 2 dikembangkan dengan tujuan memudahkan non-programmer yang ingin menciptakan game secara drag and drop dengan editor visual dan berbasis sistem logika perilaku. Editor visual adalah tempat dimana objek-objek diletakkan atau dibuat, adapun 
pengaturan logika perilaku masing-masing objek yang dinamakan event dan dituliskan dalam event sheet. Event dalam Construct 2 merupakan kumpulan dari conditions dan actions. Conditions menjelaskan kondisi objek yang ada, sedangkan actions adalah aksi yang menggerakkan objek-objek tersebut. Menurut Gullen (Apriyanto, 2016: 67) Construct 2 dirancang untuk pengembangan game berbasis 2D. Dengan Construct 2, pengembang dapat mem-publish aplikasinya dalam beberapa platform, antara lain: HTML 5 Website, Google Chrome Webstorage, Facebook, Phonegap (Android), dan Windows Phone 8.

Berdasarkan permasalahan yang telah diuraikan, maka dilakukan penelitian pengembangan dengan tujuan penelitian untuk mengembangkan produk Pocket Book Mathematic (Pockemath) berbasis android sebagai media pembelajaran yang layak dan praktis digunakan oleh siswa dalam mempelajari materi bangun ruang.

\section{B. Metodologi Penelitian}

1. Model dan Rancangan Penelitian

Model penelitian yang digunakan dalam penelitian ini adalah desain penelitian pengembangan model Four-D (Four D Models) menurut Thiagarajani. Hal ini meliputi 4 tahap yaitu tahap pendefinisian (define), perancangan (design), pengembangan (develop) dan diseminasi (disseminate). Rancangan penelitian ini dapat ditunjukan oleh gambar berikut (Nurmala 2019):

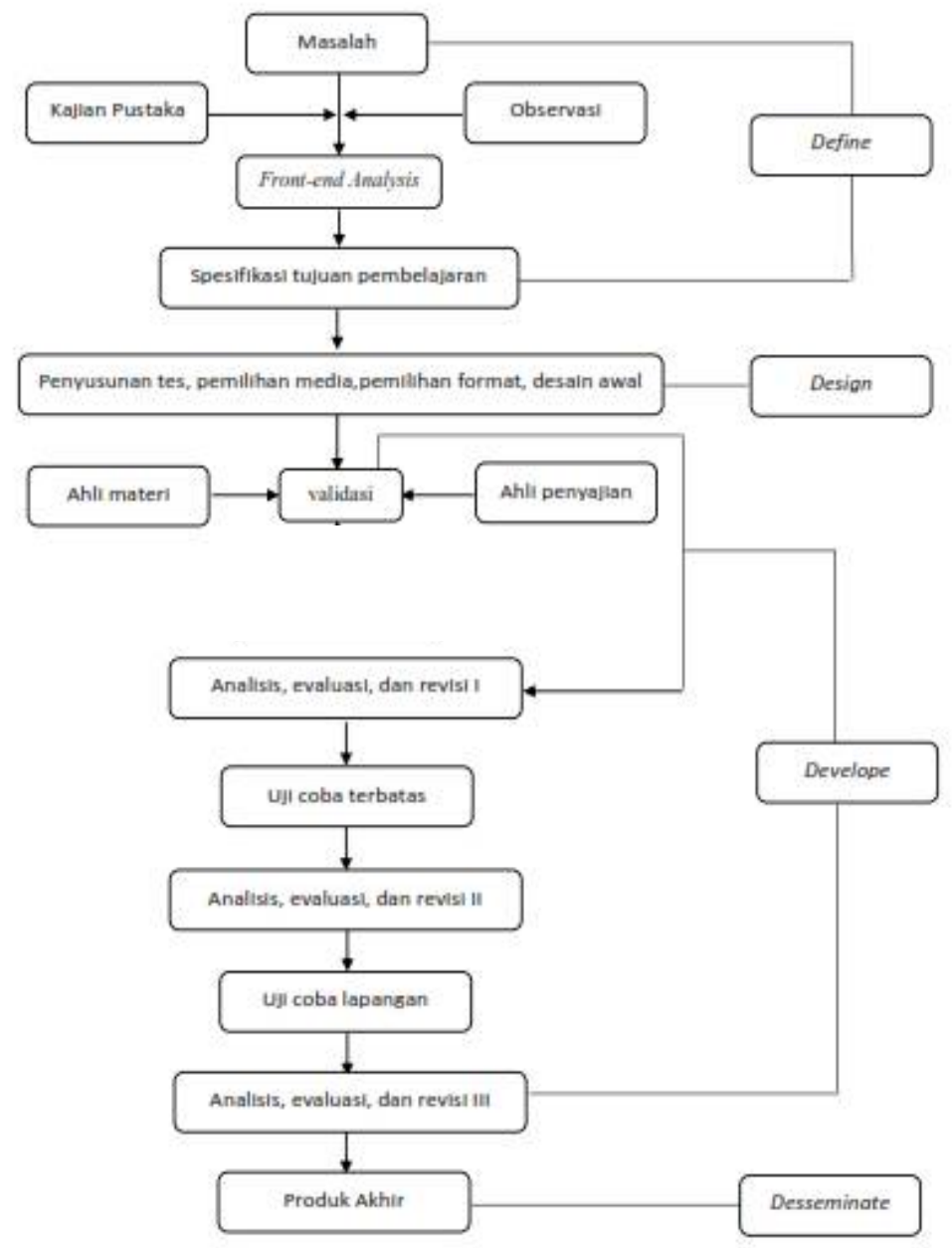

Gambar 1. Bagan Alir Penelitian \& Pengembangan Model 4-D (Sumber: Diadaptasi dari Thiagarajan) 
2. Pengumpulan Data

Data dalam penelitian ini diambil oleh peneliti dengan menetapkan beberapa teknik dan instrumen pengumpulan data sebagai berikut:

a. Dokumentasi

Dokumen yang digunakan merupakan dokumen hasil penelitian tentang pengembangan aplikasi pockemath. Peneliti juga melakukan studi refrensi baik dari buku-buku maupun internet. Semua data yang diperoleh dari dokumen ini adalah data yang mendukung pentingnya pengembangan aplikasi pockemath

b. Lembar penilaian

Lembar penilaian merupakan media untuk menilai produk yang telah dibuat oleh peneliti. Lembar penilaian diberikan kepada para ahli yang bertujuan untuk mengetahui kelayakan produk yang telah dibuat. Lembar penilaian ahli terkait dengan kelayakan isi materi dan penyajian media yang telah dibuat.

c. Lembar angket

Angket ini digunakan untuk mengetahui tanggapan siswa tentang produk yang telah dibuat. Lembar angket ini merupakan data pendukung kepraktisan dari produk yang telah dibuat.

\section{Analisis Data}

Data yang telah dikumpulkan dengan menggunakan teknik pengumulan data, selanjutnya dianalisis secara kuantitatif dan diarahkan untuk menjelaskan kelayakan dan kepraktisan produk bahan ajar yang dikembangkan. Data yang diperoleh dari hasil validasi oleh para ahli dianalisis untuk menjelaskan kelayakan produk bahan ajar yang telah dikembangkan. Adapun data hasil lembar angket digunakan untuk menjelaskan kepraktisan produk. Kriteria penilaian menggunakan acuan konversi dari Mardapi (2008: 123).

Tabel 1. Kriteria Penilaian Data Validasi Ahli dan Tanggapan Siswa

\begin{tabular}{cc}
\hline Interval Skor & Kategori \\
\hline$X>M i+1 . S b i$ & Sangat Baik \\
$M i<X \leq M i+1 . S b i$ & Baik \\
$M i-1 . S b i<X \leq M i$ & Kurang \\
$X<M i-1 . S b i$ & Sangat Kurang \\
\hline
\end{tabular}

Keterangan:

Mean Ideal (Mi) $\quad: \frac{1}{2}$ (skor tertinggi ideal + skor terendah ideal)

Simpangan Baku Ideal (Sbi) : $\frac{1}{6}$ (skor tertinggi ideal - skor terendah ideal)

$\mathrm{X}$

: Skor yang diperoleh

Skor tertinggi ideal : jumlah pernyataan $\times$ skor teringgi tiap pernyataan

Skor terendah ideal $\quad$ : jumlah pernyataan $\times$ skor terendah tiap pernyataan

Tabel 2. Skala Persentase Kelayakan Media

\begin{tabular}{cc}
\hline Persentase Pencapaian & Interpretasi \\
\hline $76 \%-100 \%$ & Sangat Layak \\
$51 \%-75 \%$ & Layak \\
$26 \%-50 \%$ & Cukup Layak \\
$0 \%-25 \%$ & Kurang Layak \\
\hline
\end{tabular}

Sumber: Arikunto (Fauzan, 2011: 35)

Kriteria kelayakan media yang dikembangkan dapat dikatakan sudah layak digunakan apabila hasil penelitian dari ahli media ali desain pembelajaran, dan ahli materi memperoleh kategori minimal layak. 
Tabel 4.Skala Persentase Kepraktisan Media

\begin{tabular}{cc}
\hline Persentase Pencapaian & Interpretasi \\
\hline $75.01 \%-100 \%$ & Sangat Praktis \\
$50,01 \%-75,00 \%$ & Praktis \\
$25,01 \%-50,00 \%$ & Kurang Praktis \\
$0 \%-25,00 \%$ & Tidak Praktis \\
\hline
\end{tabular}

Sumber: Akbar (Kumalasari, 2018: 5)

Kriteria kepraktisan produk yang dikembangkan dapat dikatakan sudah praktis digunakan siswa jika memperoleh kategori minimal praktis.

\section{Hasil Penelitian dan Pembahasan}

Tahap yang dilakukan pada penelitian dan pengembangan media pembelajaran pockemath disesuaikan dengan model yang ditemukan oleh Thiagarajan, Semmel \& Semmel yang dimodifkasi yaitu model Four-D (4D) yang terdiri dari 4 tahapan pengembangan yaitu Pendefinisian (Define), Perancangan (Design), Pengembangan (Develop), dan Deseminasi (Desseminate) (Thiagarajan, Semmel \& Semmel, 1974). Adapun tahapannya sebagai berikut:

\section{Pendefinisian (Define)}

Pada tahap pendefinisian (define) merupakan tahapan analisis dan identifikasi masalah untuk memperoleh berbagai informasi yang berkaitan dengan produk yang akan dikembangkan. a. Analisis Awal-Akhir

Analisis ini dilakukan denganmelakukan pengamatan secara langsung dan juga melakukan wawancara baik kepada guru matematika dan siswa terkait ketertarikan terhadap pembelajaran matematika kepada siswa. Hal ini dilakukan untuk mengetahui seberapa besar persentase ketertarikan siswa terhadap pembelajaran matematika.

b. Analisis Siswa

Pada tahap ini, peneliti mengalisis karakter siswa yaitu siswa lebih suka belajar sambil bermain yang ditunjukkan berdasarkan hasil observasi serta materi yang dirasa sulit bagi siswa berdasarkan wawancara peneliti dengan siswa. Kemudian dapat ditentukan media pembelajaran seperti apa yang dapat dikembangkan oleh peneliti untuk siswa di sekolah tersebut.

c. Analisis Konsep

Analisis konsep dilakukan dengan cara mengidentifikasi hal-hal yang disajikan pada produk media pembelajaran yang akan dikembangkan dengan mengacu pada silabus yaitu berupa materi pelajaran dan soal-soal tentang bangun ruang serta mengumpulkan sumbersumber untuk mendukung penyusunan soal pada media pembelajaran yang telah dikembangkan.

d. Perumusan Tujuan Pembelajaran

Pada langkah ini peneliti mengembangkan media pembelajaran pockemath untuk siswa yang layak dan praktis sesuai dengan kompetensi dasar dan indikator ketercapaian kompetensi yang telah ditetapkan pada analisis konsep sehingga setelah menggunakan media pembelajaran diharapkan tujuan pembelajaran dapat tercapai dengan baik dan minat belajar siswa terhadap matematika dapat meningkat.

\section{Perancangan (Design)}

Tujuan dari tahap ini adalah untuk merancang produk media pembelajaran yang akan dirancang khusus materi Bangun Ruang. Pada tahap perancangan ini terdiri dari empat langkahlangkah yaitu penyunsunan tes, pemilihan media, pemilihan format dan perancangan awal (desain awal). 
a. Penyusunan Tes

Pada langkah ini peneliti menyunsun tes yang berupa lembar angket yaitu angket validai media, validasi isi/materi, dan angket respon siswa yang akan digunakan sebagai alat ukur untuk mengetahui kelayakan dan kepraktisan produk.

Pada langkah ini peneliti memilih dan menentukan media yang tepat untuk penyajian materi pelajaran yang disesuaikan dengan analisis tugas, analisis konsep, dan karakteristik siswa. Maka dari itu peneliti mengembangkan media pembelajaran pockemath berbasis android yang bersifat userfriendly bisa digunakan dan dimainkan siswa baik di sekolah maupun di luar sekolah

b. Pemilihan Format

Format untuk angket minat belajar siswa disusun mengacu pada indikator minat belajar siswa. Format media pembelajaran pockemath berbasis android akan dibuat berwarna dan semenarik mungkin yang di dalamnya berisi materi dan soal latihan serta animasi produk dalam menyelesaikan soal latihan untuk kemudian diharapkan penerapannya berdampak pada peningkatan minat belajar siswa teradap pelajaran matematika.

c. Perancangan Awal (Desain Awal)

Pada langkah ini peneliti menyusun desain media pembelajaran yang dibuat dengan menggunakan aplikasi Construct 2 untuk menghasilkan sebuah media pembelajaran yang diberi nama pockemath. Isi dari media pembelajaran tersebut yaitu penjelasan singkat tentang materi Bangun Ruang serta beberapa level produk yang di dalamnya berisi latihan-latihan soal yang dapat dikerjakan oleh siswa dengan waktu yang telah ditentukan. dibawah ini diberikan contoh lembar kerja (Event Sheet) pada aplikasi Construct 2 pada pembuatan media pembelajaran pockemath:

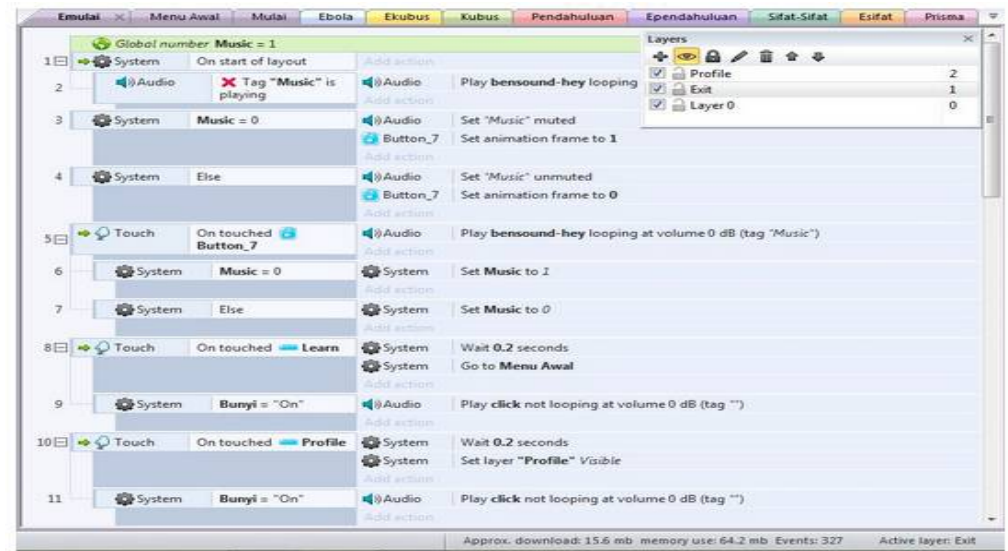

Gambar 2. Tampilan Event Sheet pada menu awal POCKEMATH

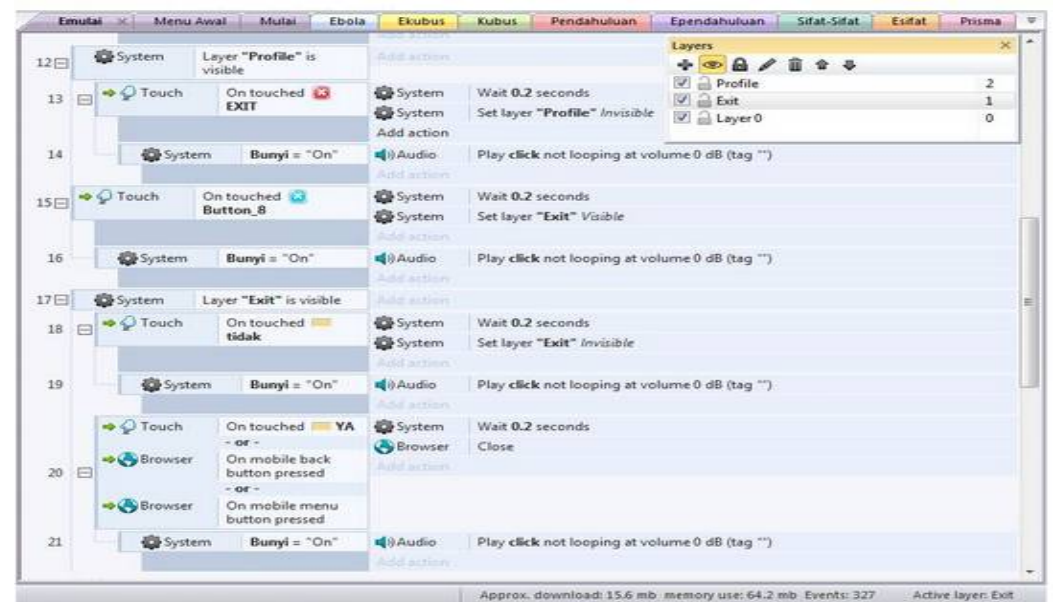

Gambar 3. Tampilan Event Sheet menu profil POCKEMATH 
Selama proses pengembangan dan penyusunan naskah media pockemath, peneliti juga melakukan uji coba terhadap media pockemath sekaligus melakukan evlauasi. Evaluasi yang dilakukan adalah dengan menguji apakah produk sudah berjalan dengan semestinya serta dengan memperhatikan apakah terdapat kesalahan penulisan atau tampilan pockemath. Aplikasi pockemath yang dirasa dapat berjalan dengan semestinya, proses selanjutnya adalah mengeksport program pockemath yang akan berbentuk format APK dan produk siap digunakan pada smartphone berbasis android.

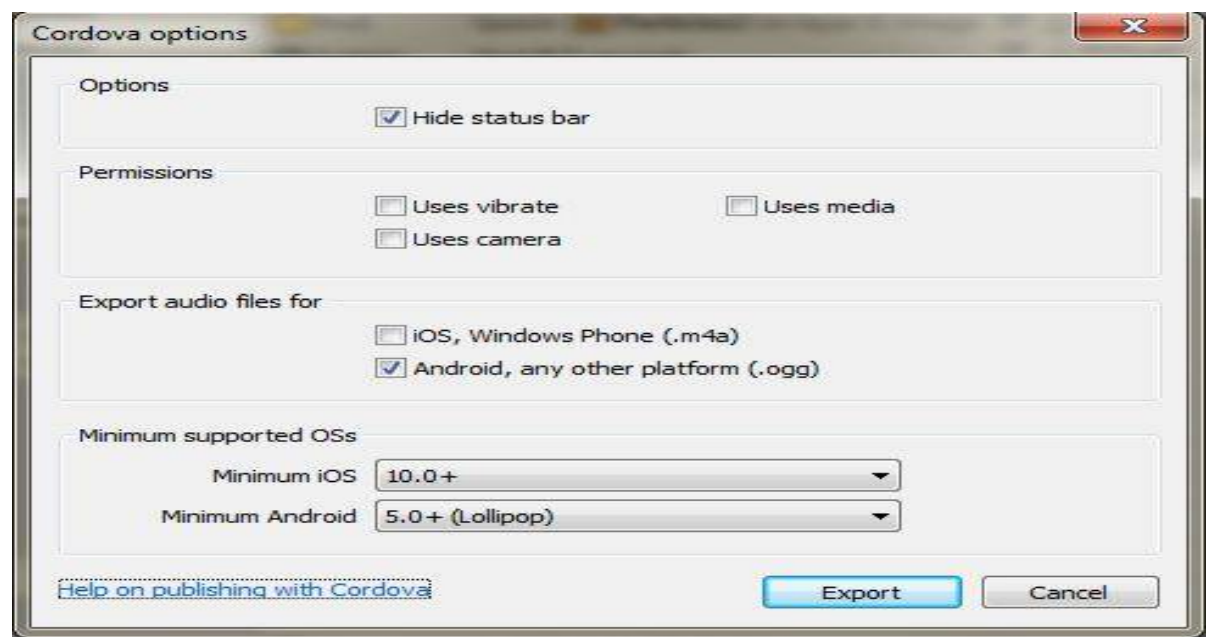

Gambar 4 Tampilam menu export pada aplikasi Construct 2

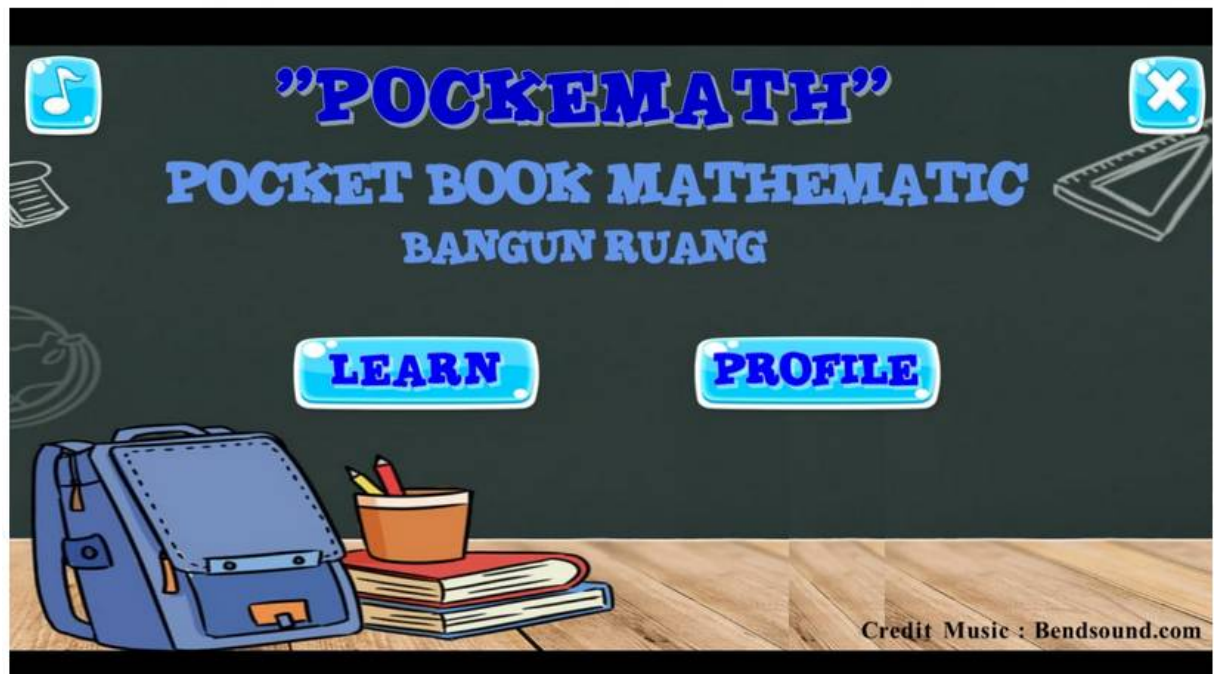

Gambar 5 Tampilam Slide awal pada aplikasi di smartphone

\section{Pengembangan (Develop)}

Tujuan dari tahap pengembangan adalah untuk menghasilkan media pembelajaran yang telah direvisi berdasarkan masukan para ahli, dan data yang diperoleh dari uji coba. Kegiatan pada tahap ini adalah penilaian para ahli (validasi), dan uji coba terbatas. 


\section{a. Validasi Produk}

Tabel 5. Hasil Penilaian Para Ahli/Validator

\begin{tabular}{cccc}
\hline Aspek Penilaian & Hasil Penilaian & Skor Maksimal & Persentase \\
\hline Media & 28,5 & 36 & $79,16 \%$ \\
Isi/Materi & 29,5 & 36 & $81,94 \%$ \\
Total Skor & $\mathbf{5 8}$ & $\mathbf{7 2}$ & $\mathbf{8 0 , 5 5 \%}$ \\
Kategori & & Sangat Layak & \\
\hline
\end{tabular}

Tabel 6. Saran Perbaikan Ahli Media

\begin{tabular}{cll}
\hline No. & \multicolumn{1}{c}{$\begin{array}{c}\text { Bagian yang salah atau } \\
\text { kurang }\end{array}$} & \multicolumn{1}{c}{ Saran Perbaikan } \\
\hline 1 & $\begin{array}{l}\text { Ketika masuk aplikasi terjeda } \\
\text { layar menghitam beberapa saat } \\
\text { baru masuk ke menu }\end{array}$ & $\begin{array}{l}\text { Perbaikan agar begitu masuk aplikasi tidak terjeda masuk } \\
\text { menu awal }\end{array}$ \\
\hline 2 & $\begin{array}{l}\text { Tampilan awal terlihat biasa } \\
\text { saja }\end{array}$ & Buatkan slide awal yang menampilkan judul aplikasi \\
\hline 3 & Tidak ada tombol keluar/exit & $\begin{array}{l}\text { Sebaiknya menambahkan 1 tomol untuk exit/keluar pada } \\
\text { layer pertama, dan pada tombol tersebut munculkan } \\
\text { pertanyaan apakah anda ingin keluar atau tidak (ada } \\
\text { pilihan ya atau tidak) }\end{array}$ \\
\hline 4 & $\begin{array}{l}\text { Setiap menekan tombol menu, } \\
\text { lambat respon }\end{array}$ & $\begin{array}{l}\text { Perbaikan terhadap setiap tombol dapat merespon cepat } \\
\text { tanpa harus menunggu lama }\end{array}$ \\
\hline 5 & $\begin{array}{l}\text { Tidak ada sound sehingga } \\
\text { aplikasi terlihat sepi }\end{array}$ & $\begin{array}{l}\text { Tambahkan sound pada aplikasi setiap slide (yang bisa di } \\
\text { stel bunyinya diperbesar atau diperkecil atau disesuaikan } \\
\text { tetapi bisa di on off kan) }\end{array}$ \\
\hline 6 & $\begin{array}{l}\text { Tombol exit setiap slide tidak } \\
\text { konsisten }\end{array}$ & $\begin{array}{l}\text { Sebaiknya tombol exit setiap slide konsisten berada } \\
\text { sebelah kanan ujung atas. }\end{array}$ \\
\hline 7 & $\begin{array}{l}\text { Tidak ada profil pembuat } \\
\text { aplikasi }\end{array}$ & \begin{tabular}{l} 
Menambahkan tab profil \\
\hline
\end{tabular}
\end{tabular}

Tabel 7. Saran Perbaikan Ali Isi/Materi

\begin{tabular}{lll}
\hline No. & \multicolumn{1}{c}{ Bagian yang salah atau kurang } & \multicolumn{1}{c}{ Saran perbaikan } \\
\hline 1. & $\begin{array}{l}\text { Di bagian rumus-rumus hanya menampilkan } \\
\text { rumus saja }\end{array}$ & $\begin{array}{l}\text { Sebaiknya tambahkan gambar bangun } \\
\text { ruang sebelum menampilkan dibagian } \\
\text { bawahnya rumus-rumus dr bangun ruang } \\
\text { tersebut. }\end{array}$ \\
2 & Tidak memuat semua bangun ruang & $\begin{array}{l}\text { Tambahkan materi bangun ruang lainnya } \\
\text { yaitu: tabung, kerucut, dan bola }\end{array}$ \\
3 & $\begin{array}{l}\text { Tidak ada contoh soal sebagai tambahan } \\
\text { pemahaman terhadap materi oleh siswa }\end{array}$ & $\begin{array}{l}\text { Tambah } 1 \text { tab dibawah rumus-rumus } \\
\text { yaiu tab: contoh soal/latihan soal }\end{array}$ \\
\hline
\end{tabular}

\section{b. Uji Coba}

Setelah dilakukan revisi produk sesuai saran dari para ahli, kemudian dilanjutkan pada tahap uji coba produk terbatas yang terdiri dari 5 orang siswa. Setelah dilakukan uji coba produk kelompok kecil produk pockemath, kemudian dilanjutkan pada tahap uji coba produk lapangan yang terdiri dari 30 orang siswa. Uji Coba kelompok kecil dan uji coba lapangan dilakukan untuk melihat kepraktisan produk yang telah dikembang dengan menggunakan angket respon 
siswa terhadap produk pockemath berbasis android. Berdasarkan hasil uji coba yang ditelah dilakukan, maka diperoleh data respon siswa terhadap media pembelajaran pockemath yang dapat dilihat pada tabel dibawah ini.

Tabel 8. Hasil Data Respon Siswa

\begin{tabular}{lccc}
\hline \multicolumn{1}{c}{ Subjek Uji Coba } & Hasil Penilaian & Skor Maksimal & Persentase \\
\hline Kelompok Kecil & 33,4 & 36 & $92,77 \%$ \\
Lapangan & 32,26 & 36 & $89,61 \%$ \\
\hline Total Skor & $\mathbf{6 5 , 6 6}$ & $\mathbf{7 2}$ & $\mathbf{9 1 , 1 9 \%}$ \\
\hline Kategori & & & Sangat Praktis \\
\hline
\end{tabular}

Berdasarkan tabel diatas, rata-rata hasil uji coba produk terbatas pada aspek kemudahan produk untuk dioperasikan pada angket memperoleh skor 33,4 dengan kategori Baik, sehingga pada aspek kemudahan produk untuk dioperasikan yang disajikan dapat digunakan sebagai bahan pada produk media pembelajaran pockemath. Selanjutnya, rata-rata hasil uji coba produk lapangan pada aspek kemudahan produk untuk dipelajari pada angket memperoleh skor 32,26 dengan kategori Sangat Baik, sehingga pada aspek keindahan dan kemudahan produk untuk dipelajari yang disajikan dapat digunakan sebagai bahan pada produk media pembelajaran pockemath.

\section{Penyebarluasan (Disseminate)}

Produk yang telah direvisi, selanjutnya diseminasi (disebarluaskan). Pada tahap ini penyebaluasan dilakukan secara terbatas yaitu dengan menyerahkan aplikasi ke guru-guru matematika di sekolah tempat uji coba dilakukan. Tahap ini dilakukan agar produk pockemath dapat dimanfaatkan oleh sekolah tersebut. Produk pockemath dikemas (packaging) dalam bentuk Flashdisk dan disebarluaskan agar dapat diserap (diffusi) dan digunakan (diadopsi) pada pembelajaran matematika. Peneliti tidak melakukan tahap penyebaran secara lebih luas lagi dikarenakan membutuhkan biaya yang banyak dan waktu yang lama.

Berdasarkan hasil penelitian yang diperoleh, media pembelajaran matematika pockemath yang dikembangkan dalam kategori sangat layak dan sangat praktis, hal tersebut tercermin dari hasil validasi yang ditunjukkan pada tabel Hasil Penilaian Para Ahli/Validator dan pada tabel Hasil Data Respon Siswa. Sehingga media pockemath berbasis android sebagai media pembelajaran layak dan praktis digunakan dalam pembelajaran matematika. Hasil pengembangan media ini sejalan dengan penelitian Larasyati bawha media Pocket Book Of Physics (PBOP) berbasis android sebagai media pembelajaran fisika dikembangkan dalam penelitian ini dikategorikan baik dan layak digunakan dalam pembelajaran. Sedangan dalam kajian oleh A.H.Ngurahrai yang mengkaji tentang pengembangan media berbasil mobil $e$ learning berbasis android untuk pembelajaran fisika bahwa media sejatinya dirancang dan dikembangkan sebagai sarana penyampai pesan agar lebih bermakna dan memberikan pemahaman konsep maupun analisis pada pembelajaran yang lebih baik.

\section{Kesimpulan}

Dari hasil penelitian yang dilakukan maka diperoleh produk pengembangan yang dihasilkan sesuai dengan tujuan pengembangan yaitu berdasarkan hasil validasi oleh pakar, diperoleh bahwa produk Pocket Book Mathematic (Pockemath) berbasis android yang dikembangkan layak untuk digunakan sebagai media pembelajaran matematika. Berdasarkan uji coba yang telah dilaksanakan, diperoleh bahwa produk Pocket Book Mathematic 
(Pockemath) berbasis android yang dikembangkan praktis digunakan dalam proses pembelajaran matematika. Dengan demikian, dengan memanfaatkan media pembelajaran Pocket Book Mathematic (Pockemath) berbasis android yang berisi materi bangun ruang dapat memberikan dampak positif dalam pembelajaran matematika yang dapat digunakan oleh siswa kapanpun dan dimanapun karena media pockemath ini bersifat userfriendly.

Diharapkan media yang telah dikembangkan ini berupa pockemath dapat digunakan oleh siswa sebagai sumbel belajar tambahan dalam mempelajari materi bangun ruang. Untuk penelitian selanjutnya hendaknya dapat membuat media pembelajaran lainnya seperti pockemath dengan materi yang berbeda, perlu dikaji penggunaan media pembelajaran pockemath terhadap hasil belajar siswa. Hal ini dimaksudkan agar media pockemath bukan hanya diketahui pada materi bangun ruang, akan tetapi juga dapat dikembangkan pada materi matematika lainnya.

\section{E. Acknowledgement}

Sebagai penghargaan, kami menyampaikan terima kasih kepada Universitas Borneo Tarakan atas pendanaan DIPA UBT tahun anggaran 2021, sehingga penelitian ini dapat terlaksana dengan baik.

\section{DAFTAR PUSTAKA}

A. H. Ngurahrai, S. D. Fatmaryanti, and N. Nurhidayati. Pengembangan Media Pembelajaran Fisika Berbasis Mobile Learning Untuk Meningkatkan Kemampuan Berpikir Kritis Peserta Didik. Radiasi, vol. 12, no. 2, pp. 76-83, Sep. 2019.

Arikunto, S. (2012). Dasar-dasar Evaluasi Pendidikan. Jakarta: Bumi Aksara.

Apriyanto. 2016. Pembuatan Game Labirin Menggunakan Aplikasi Construct 2 Berbasis Online. Jurnal Elektronik Sistem Informasi dan Komputer Vol. 2, No. 2, Hal. 64-72.

Daryanto. (2013). Media pembelajaran (perannya sangat penting dalam mencapai tujuan pembelajaran). Yogyakarta: Gava Media

Fauzan, Ahmad. 2011. Analisis Kelayakan Media Pembelajaran Perakitan Komputer Untuk Siswa Sekolah Menengah Kejuruan. SKRIPSI. Fakultas Teknik. Universitas Negeri Yogyakarta.

Kumalasari, Maharani Putri. 2018. Kepraktisan Penggunaan Multimedia Interaktifpada Pembelajaran Tematik Kelas IV SD. Jurnal Bidang Pendidikan Dasar (JBPD) Vol. 2, No. 1A, Hal 1-11.

Kustini, S., \& Nurkhin, A. (2011). Teknologi Informasi dan Komunikasi dalam Pembelajaran Akuntansi (Studi Empiris Pada Guru SMK Se Kota Semarang). Jurnal pendidikan ekonomi dinamika pendidikan, Volume 6 No 1 tahun 2011.

Kusumaningtyas, Nopem \& Listiani, Welas. (2017). Pengembangan Media Cergam Untuk Meningkatkan Minat Belajar Matematika Pada Siswa Sekolah Dasar di Daerah 
Tertinggal. Jurnal Filsafat, Sains, Teknologi, dan Sosial Budaya. Volume 23, Nomor 1, Januari - Juni 2017

Larasyati, K.K, Fatmaryanti, Siska D.,\& Hakim, Yusro. 2020. Pengembangan Pocket Book Of Physics (PBOP) Berbasis Android Sebagai Media Pembelajaran Fisika. JIPS: Jurnal Inovasi Pendidikan Sains. Volume 1 Nomor 2, November, 2020, pp: 68-72

Mardapi, Djemari. 2008. Teknik Penyusunan Instrumen Tes dan Nontes. Yogyakarta: Mitra Cendikia Offset.

Muhson, Ali. 2010. Pengembangan Media Pembelajaran Berbasis Teknologi Informasi. Jurnal Pendidikan Akuntansi Indonesia Vol. 8, No. 2, Hal 1-10.

Negara, Habib R. P., dkk. 2019. Meningkatkan Minat Belajar Siswa Melalui Pemanfaatan Media Belajar Berbasis Android menggunakan MITT APP INVENTOR. Jurnal Pengabdian Masyarakat Berkemajuan Vol. 2, No. 2, Hal. 42-45.

Netriwati dan Mai Sri Lena. (2017). Media Pembelajaran Matematika. Lampung: Permata

Nurmala R \& Susanti, Dwi. (2019) Pengembangan Bahan Ajar Trigonometri berbasis Literasi Matematika. Jurnal Borneo Saintek ISSN (online) 2599-3313 dan ISSN (cetak) 2615 434X Vol 2. No 1 April 2019

Nurmala R, Mucti ,Alfian, Izzatin, Maharani (2019). Desain Pengembangan Buku Matematika SMP Berbasis Android Sebagai Media Pembelajaran Dalam Meningkatkan Minat Belajar Siswa. Jurnal Edukasia Volume 6 No. 2

Rina, Yuliana. 2017. Pengembangan Perangkat Pembelajaran dengan Pendekatan PMRI pada Materi Bangun Ruang Sisi Lengkung untuk SMP Kelas IX. Yogyakarta,vol. 6,no. 1 (http://journal.student.uny.ac.id, diakses 25 Mei 2021)

Sadiman, Arief S. 2014. Media Pendidikan Pengertian, Pengembangan, dan Pemanfaatannya. Jakarta: PT. Raja Grafindo Persada.

Satyaputra dan Aritonang. 2014. Beginning Android Programming With ADT Budle. Jakarta: Elex Media Komputindo.

Thiagarajan, S., Semmel, D.S., \& Semmel, M.I. (1974). Instructional development for training teacher of exceptional children. Bloomington Indiana: Indiana University. 